\title{
DESENVOLVIMENTO DO AÇO FB580-EG PARA APLICAÇÃO NA INDÚSTRIA AUTOMOTIVA*
}

\author{
Fernando de Souza Costa ${ }^{1}$ \\ Carlos Augusto Carvalhido ${ }^{2}$ \\ Fagner de Carvalho Oliveira ${ }^{3}$ \\ Gleyder Oliveira Bustamante 4 \\ Rafael Fagundes Ferreira ${ }^{5}$
}

\section{Resumo}

Nos últimos anos a indústria automotiva vem conseguindo avançar de forma contínua em relação ao controle da emissão de $\mathrm{CO}_{2}$ e no tocante à segurança veicular. $\mathrm{O}$ aumento da utilização de aços de alta resistência mecânica se constitui num dos principais sustentáculos destas melhorias. Além disso, na manufatura de certas peças, em especial as de geometria complexa, é fator crítico de sucesso a capacidade do material em absorver intensas deformações localizadas, tipicamente encontradas em operações de expansão de furo. $\mathrm{O}$ aço desenvolvido pela Usiminas é um produto laminado a frio, com revestimento eletrogalvanizado, da classe de 600 MPa de limite de resistência, com boas propriedades de flangeamento de bordas e de alongamento em tração. Neste trabalho, é apresentado o desenvolvimento deste aço. São descritas as suas principais características e os resultados de sua aplicação em uma peça de geometria complexa.

Palavras-chave: Aços Ferrita-Bainita; Expansão de furo; Flangeamento de borda.

\section{DEVELOPMENT OF FB580-EG STEEL FOR AUTOMOTIVE APPLICATION Abstract}

In the course of the recent years the automotive industry has been able to move continuously in the control of $\mathrm{CO}_{2}$ emissions and as well as regarding the vehicle safety. The increased use of high strength steels constitutes one of the keys of these improvements. Furthermore in the manufacturing of certain parts, particularly those of complex geometry, it is critical success factor the ability of a material to absorb intense localized deformations typically found in hole expansion operations. The steel developed by Usiminas is an electrogalvanized cold-rolled product, $600 \mathrm{MPa}$ tensile strength grade with good properties of stretchflangeability and elongation. In this work, the development of this steel is presented. The paper describe its main characteristics and the results of its application in a complex part geometry.

Keywords: Ferrite-Bainite steel; Hole expansion ratio; Stretchflangeability.

1 Físico, M.Sc., D.Sc., Pesquisador Especialista Pleno, Pesquisa e Desenvolvimento de Produtos, Usiminas, Ipatinga, MG, Brasil.

2 Engenheiro Metalurgista, M.Sc., Especialista de Produto, Atendimento ao Cliente, Garantia da Qualidade e Produto, Usiminas, Belo Horizonte, MG, Brasil.

3 Engenheiro Metalurgista, Engenheiro de Produto Pleno, CQE, Controle Integrado do Produto, Usiminas, Ipatinga, MG, Brasil.

4 Engenheiro Metalurgista, M.Sc, CQE, Especialista de Assistência Técnica, Atendimento ao Cliente, Garantia da Qualidade e Produto, Usiminas, Belo Horizonte, MG, Brasil.

5 Engenheiro Mecânico, M.Sc., Engenharia de Materiais e Ecologia do Produto, Fiat Chrysler Automobiles, Betim, MG, Brasil. 


\section{INTRODUÇÃO}

Nos últimos anos a indústria automobilística vem empreendendo esforços contínuos com o objetivo de minimizar a emissão de gases poluentes e melhorar a segurança dos veículos. Dentre as ações implementadas, merece destaque o emprego crescente de aços de alta resistência, a fim de reduzir o peso dos automóveis. Se inicialmente as atenções estavam voltadas quase que exclusivamente para peças de reforço estrutural, de geometria simples, os esforços agora se voltam também para reduzir o peso de peças de geometria complexa, cujo sucesso em sua fabricação requer aços mais sofisticados, com características específicas, sendo a elevada capacidade de flangeamento de borda e uma boa capacidade de alongamento, as mais evidentes.

Neste contexto, a demanda do mercado automotivo por um aço da classe de $600 \mathrm{MPa}$ de limite de resistência com requisito de expansão de furo mínimo de $75 \%$, levou a equipe da Usiminas a desenvolver, em um curto período de tempo, o aço FB580-EG, que é um produto laminado a frio com revestimento eletrogalvanizado.

Diante da necessidade de desenvolver um novo aço, a Usiminas elaborou um plano de desenvolvimento, dividido em etapas em escalas piloto e industrial, além de uma etapa de avaliação e aprovação do produto, mediante sua aplicação na fabricação de uma peça automotiva de geometria complexa, realizada em conjunto com a Engenharia de Materiais da FCA (Fiat Chrysler Automobiles).

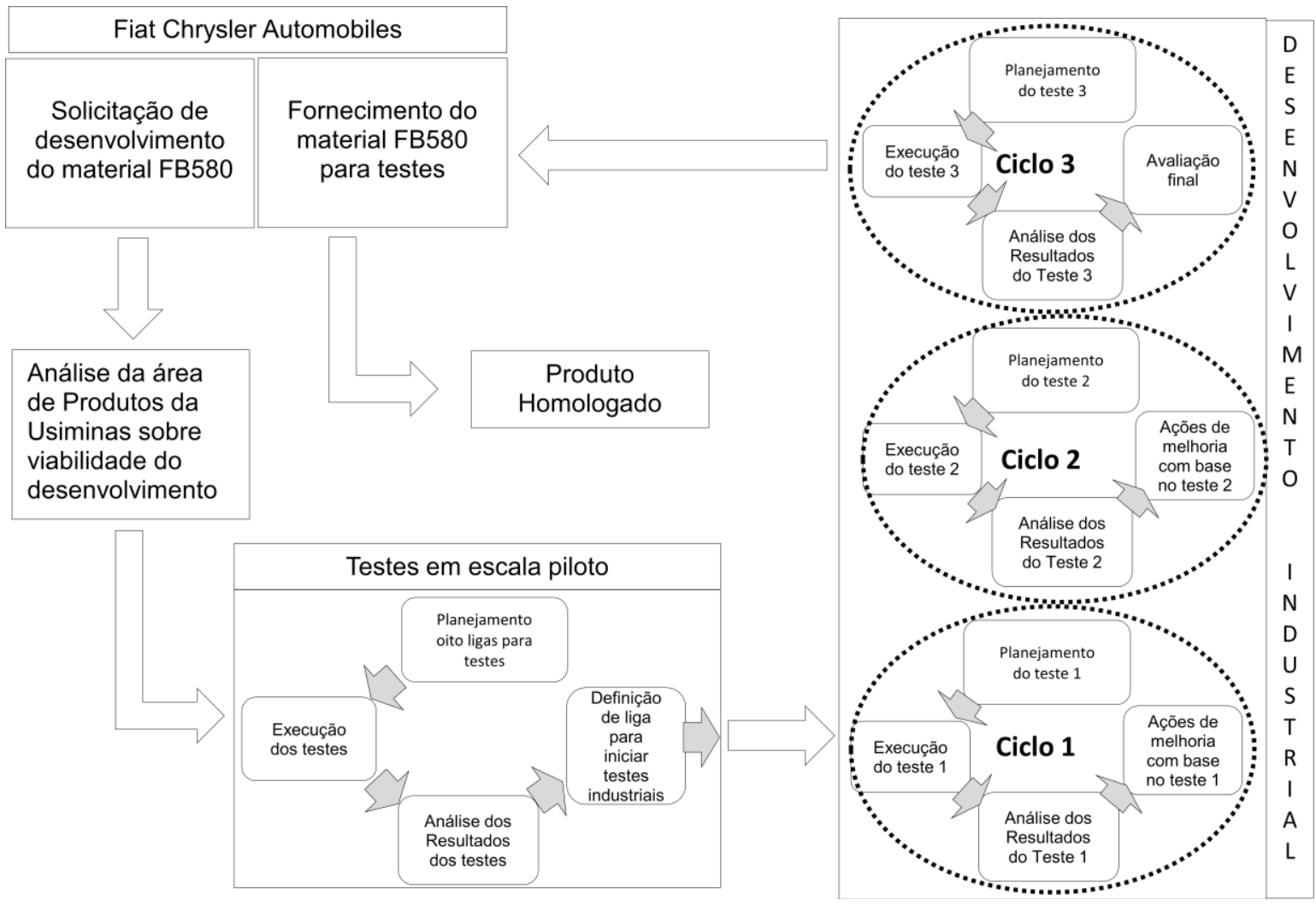

Figura 1. Representação esquemática da evolução do desenvolvimento do aço FB580.

Neste trabalho são apresentados resultados obtidos no desenvolvimento do aço FB580-EG, pela Usiminas, e as principais características do novo produto. Também são comentados os resultados de um caso de sucesso de sua aplicação. 


\subsection{O Aço Ferrita-Bainita}

O aço ferrita-bainita (FB) pode ser classificado, no tocante às suas propriedades, como sendo um produto de alta resistência mecânica, aproximadamente assemelhado, quanto ao binômio alongamento total e limite de resistência em tração, aos aços do tipo HSLA e Dual Phase, conforme está ilustrado na Figura 2. Sua característica mais notável, no entanto, é sua excepcional capacidade de absorver intensas deformações localizadas, tipicamente encontradas em operações de expansão de furos durante a manufatura das peças, mantendo, com isso, sua integridade estrutural.

As operações de expansão de furos constituem casos particulares do que se denomina flangeamento de borda, que consiste em um dobramento em linha curva. Quando o blank é dobrado em uma seção curva, o perímetro da borda de flange pode aumentar ou diminuir após flangeamento, de acordo com a geometria da peça. Baseado nesse comportamento, as operações de flangeamento são normalmente classificadas como estiramento, que ocorre em virtude da necessidade da geometria da peça expandir-se para que o dobramento seja realizado, e encolhimento, quando o material sofre uma constrição para a ocorrência do dobramento.

Em documento da WorldAutoSteel [1], a utilização do aço FB é sugerida em algumas peças, tais como: braço inferior de suspensão, barra de torção, em peça de reforço do para-choque, dentre outras.

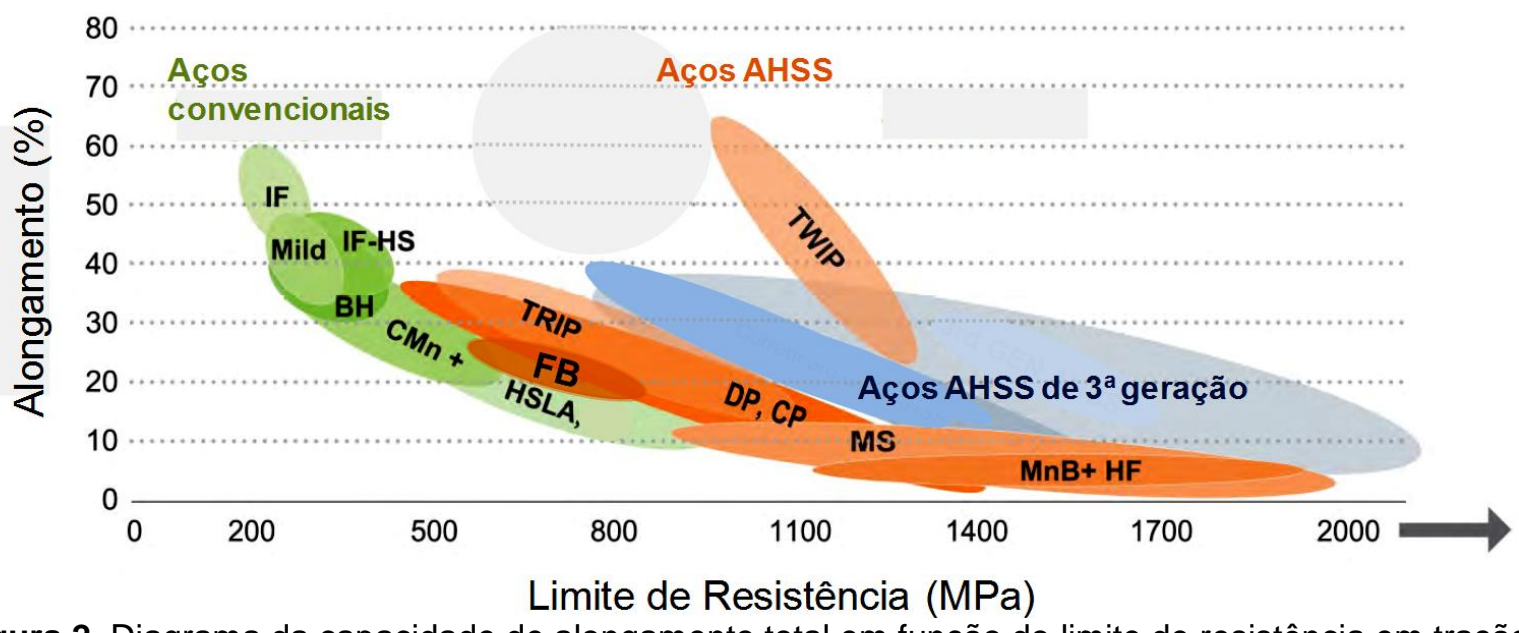

Figura 2. Diagrama da capacidade de alongamento total em função do limite de resistência em tração de vários aços empregados na indústria automotiva, listados por WorldAutoSteel [1].

O produto FB580-EG, desenvolvido pela Usiminas, conta ainda com uma camada de revestimento de zinco, depositada por processo eletrolítico, que garante a proteção do material contra a ação de agentes corrosivos.

\section{MATERIAIS E MÉTODOS}

O desafio posto no desenvolvimento do aço FB580, do ponto de vista das possíveis aplicações visadas, consistia em obter um produto capaz de combinar uma elevada capacidade de flangeamento de borda, medida no ensaio de expansão cônica de furo, com um limite de resistência em tração mínimo de $580 \mathrm{MPa}$, além de boa capacidade de alongamento em tração. A importância de garantir um adequado equilíbrio deste conjunto de propriedades pode ser percebida quando se verifica que, na manufatura de peças com geometria complexa, o material é submetido a 
diferentes solicitações mecânicas, em diferentes regiões da peça. Um bom exemplo é a peça denominada braço inferior de suspensão, que é uma das aplicações sugeridas para o aço FB580, ilustrada na Figura 3.

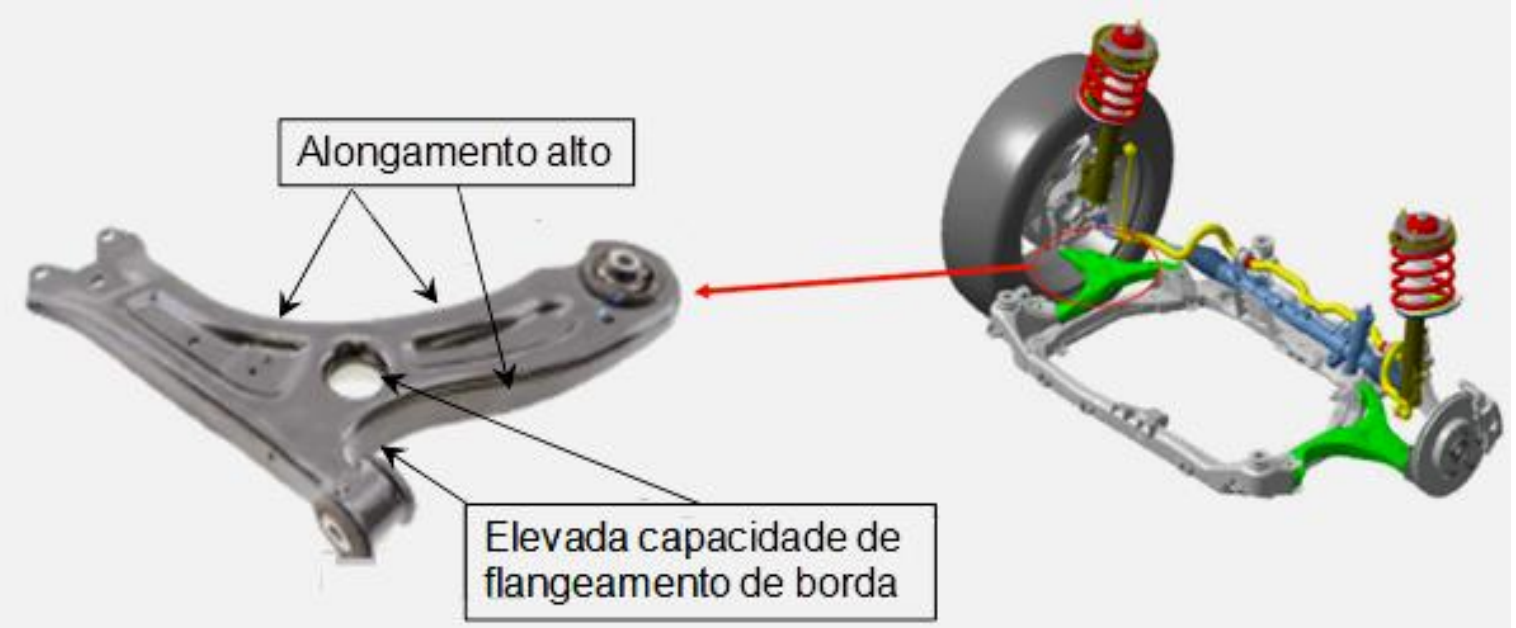

Figura 3. Aspecto e propriedades de conformação mecânica requeridas na manufatura da peça denominada braço inferior de suspensão [2].

Informações de literatura, no entanto, dão conta de que, de um modo geral, estas propriedades variam em direção contrária. Matsuoka e colaboradores [3], por exemplo, em estudo sobre um aço dual phase da classe de $1000 \mathrm{MPa}$ de limite resistência, reportaram que a capacidade de flangeamento de borda é inversamente proporcional ao alongamento total. Da mesma forma, outros trabalhos relatam que tanto a capacidade de flangeamento de borda quanto a de alongamento são deterioradas pelo aumento do nível de resistência mecânica $[4,5]$.

Embora seja possível, em princípio, buscar uma solução de equilíbrio entre estas propriedades citadas, mediante a obtenção de uma microestrutura adequada, o controle do processo para obter a microestrutura pretendida não era previamente conhecido. Além disso, a microestrutura considerada adequada depende do nível de resistência mecânica visado para o produto.

Para o aço FB580, os autores consideraram que a microestrutura desejada deveria ser constituída por matriz ferrítica, com grãos homogeneamente finos e de morfologia equiaxial, com o segundo constituinte, variando numa fração aproximada entre 15 e 20\%, sendo formado em sua maioria por bainita. A fim de minimizar a diferença de dureza entre os constituintes microestruturais, e assim melhorar a capacidade de flangeamento de borda, também foi considerada a eventual necessidade de adicionar algum elemento químico capaz de promover endurecimento por solução sólida da ferrita.

\subsection{Experiências em Escala Piloto}

Os objetivos que nortearam a etapa de experiências em escala de laboratório foram: estabelecer uma composição química com maiores chances de sucesso, para fabricar o aço FB580, e testar opções referentes ao recozimento do material, mediante simulações em escala piloto.

Para atender ao primeiro objetivo foram avaliadas oito composições químicas diferentes. A composição de referência, por ser considerada mais promissora inicialmente, foi estabelecida à base de C-Mn-Nb com adição de Si para promover 
endurecimento por solução sólida da matriz ferrítica. As demais ligas avaliadas foram selecionadas com o intuito de investigar os impactos das seguintes variações: o efeito de alterações isoladas nos teores de C e Mn; a substituição do Si pelo P; adições isoladas de $\mathrm{Cr}$ e Mo; variações no teor de $\mathrm{Nb}$.

Amostras dos materiais escolhidos foram submetidas a ensaios de simulação de ciclos de recozimento em simulador termomecânico Gleeble, modelo 3500 . Em seguida foram realizados ensaios de tração segundo a norma ASTM A 370 em corpos de prova com $25 \mathrm{~mm}$ de base de medida. Os ensaios de expansão cônica de furos foram feitos de acordo com procedimento desenvolvido no Centro de Pesquisa da Usiminas. A microestrutura das amostras foi caracterizada por microscopia óptica e via microscopia eletrônica de varredura (MEV).

Os testes realizados na etapa piloto permitiram estabelecer as faixas para a composição química a ser testada em escala industrial, que estão mostradas na Tabela 1.

Tabela 1. Faixas de composição química especificadas para os testes industriais

\begin{tabular}{cllccccc}
\hline $\mathbf{C}(\%)$ & Mn (\%) & Si (\%) & $\mathbf{P}(\mathbf{p p m})$ & $\mathbf{S}(\mathbf{p p m})$ & $\mathbf{A l}(\%)$ & $\mathbf{N}(\mathbf{p p m})$ & $\mathbf{N b}+\mathbf{T i}+\mathbf{V}(\%)$ \\
\hline$\leq 0,12$ & $\leq 2,00$ & $\leq 0,80$ & $\leq 300$ & $\leq 60$ & $\leq 0,060$ & $\leq 90$ & $\leq 0,060$ \\
\hline
\end{tabular}

Ainda na etapa piloto definiu-se, como melhor opção para a fabricação do material, a rota de produção via recozimento contínuo, com a posterior aplicação de uma camada de revestimento com zinco eletrodepositado.

\subsection{Experiências em Escala Industrial}

O material foi produzido em escala industrial conforme o seguinte fluxo: Convertedor LD, Forno Panela, Lingotamento Contínuo, Forno de Reaquecimento de Placas tipo Walking Bean, Laminadores desbatadores, Trem acabador, PLTCM (Picking Line and Tandem Cold Mill), CAPL (Continuos Annealing and Processing Line), laminador de encruamento, inspeção e amostragem.

\section{RESULTADOS E DISCUSSÃO}

\subsection{Resultados de Experiências em Escala Piloto}

A Figura 4 apresenta, de forma resumida, alguns dos resultados obtidos em escala piloto. São mostrados os valores médios do limite de escoamento (LE), do limite de resistência (LR) e do alongamento em tração, e da capacidade de expansão cônica de furo $(\lambda E F)$. 


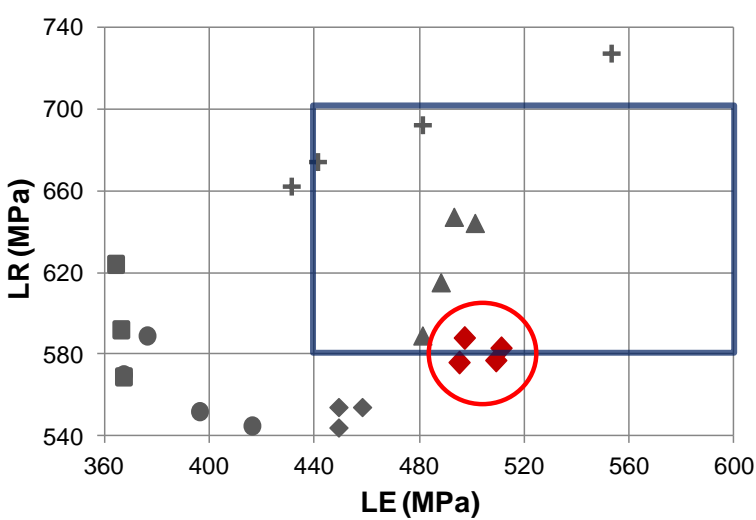

a)

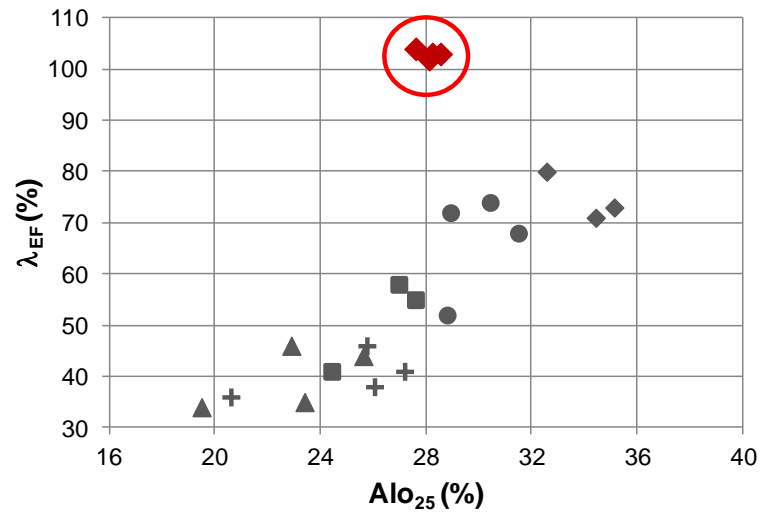

c)

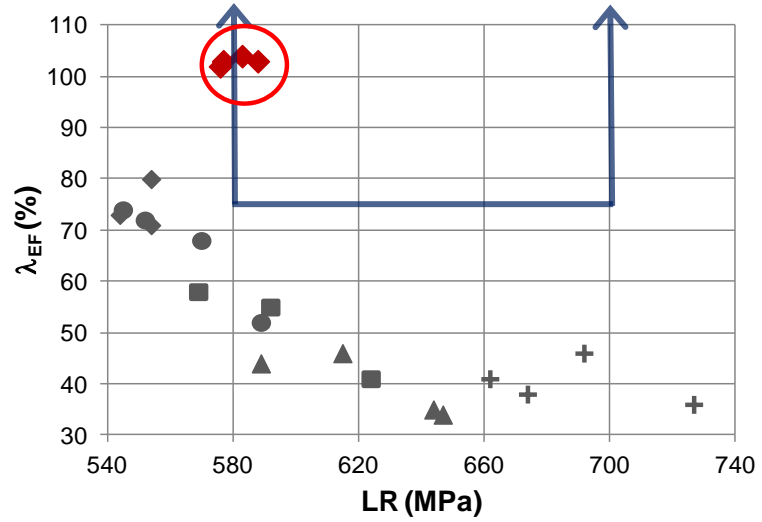

b)

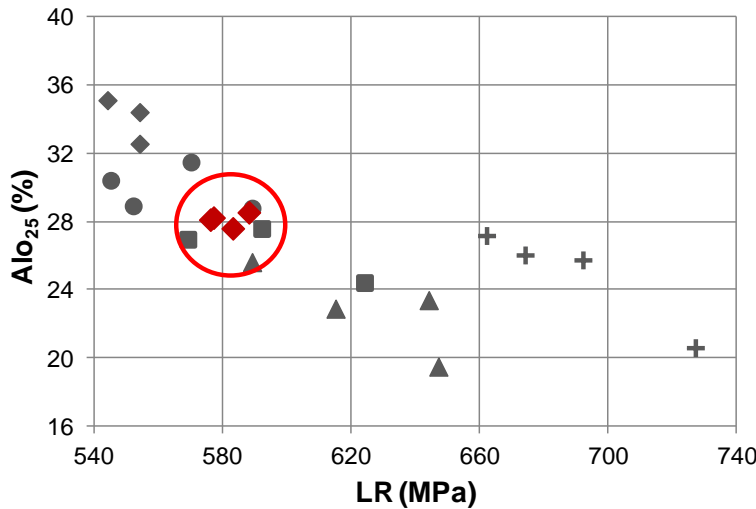

d)

Figura 4. Valores médios de LR em função de LE (a), de $\lambda_{E F}$ (expansão cônica de furo) em função de LR (b) e do alongamento em tração (c) e do alongamento em função de LR (d), das ligas avaliadas. Os círculos destacam a liga que forneceu o melhor equilíbrio entre as propriedades.

De acordo com os resultados exibidos na Figura 4, uma das ligas se destacou por apresentar valores excepcionalmente elevados de capacidade de expansão de furo. Além disso, seus resultados médios de limite de escoamento estão no centro da faixa visada. Embora os valores de LR tenham ficado próximos ao limite inferior.

Além disso, este material apresentou valores médios de alongamento total da ordem de $28 \%$ em corpos de prova (CP) com $25 \mathrm{~mm}$ de base de medida (Alo25). De acordo com um estudo interno realizado no Centro de Pesquisa e Desenvolvimento da Usiminas, em que foram levantadas correlações entre valores de alongamento para CPs com diferentes geometrias, para aços laminados a frio de diversos graus de resistência mecânica, verificou-se que o alongamento total diminui em média aproximadamente $10 \%$ do valor, quando a base de medida passa de 25 para $50 \mathrm{~mm}$ em CPs segundo a norma ASTM. Com o ajuste para $50 \mathrm{~mm}$, conforme determina a norma MS.50002 [6] da FCA, o alongamento pode ser estimado então em aproximadamente $25 \%$. Ou seja, os testes realizados em escala piloto indicaram que a liga em destaque na Figura 4 atendeu ao objetivo traçado inicialmente no tocante ao equilíbrio entre elevada capacidade de flangeamento de borda, resistência mecânica, nesse caso muito próxima ao valor mínimo visado, e alongamento em tração.

Os resultados mostrados na Figura 4(b) indicam ainda que, excetuando-se os dados da liga em destaque por meio de círculos, a capacidade de expansão cônica de furo dos demais materiais testados diminuiu com o aumento de LR, o que corrobora as informações da literatura. Por outro lado, 0 incremento dos valores $\lambda \mathrm{EF}$ com 0 
aumento do alongamento em tração, mostrado na Figura 4(c), contradiz resultados reportados na literatura [3 a 5]. Isto pode ser explicado, considerando que, de acordo com as análises metalográficas realizadas, os aços avaliados no presente estudo apresentam microestrutura constituída majoritariamente por ferrita poligonal. Nesta condição, os ajustes microestruturais necessários para melhorar a capacidade de flangeamento de borda, tais como a diminuição da quantidade de carbonetos grosseiros e maior homogeneidade entre os grãos ferríticos, também incrementam o alongamento em tração. Por outro lado, nos trabalhos consultados [3 a 5], autores trabalharam com aços de resistência mecânica mais elevada, nos quais a fração de ferrita poligonal é relativamente baixa. Nestes aços, a melhoria da propriedade de flangeamento de borda, se dá pelo aumento da fração de bainita, em detrimento da ferrita poligonal e da martensita. Em aços da classe de $1000 \mathrm{MPa}$ de limite de resistência, com elevada capacidade de flangeamento de borda, a microestrutura do material é predominantemente bainítica, com a ferrita poligonal e a martensita sendo constituintes minoritários. Em uma microestrutura com estas características, os ganhos em capacidade de flangeamento de borda são obtidos com perdas inerentes no alongamento em tração.

O aspecto típico da microestrutura do produto, que melhor se destacou na etapa piloto, está mostrado na Figura 5.

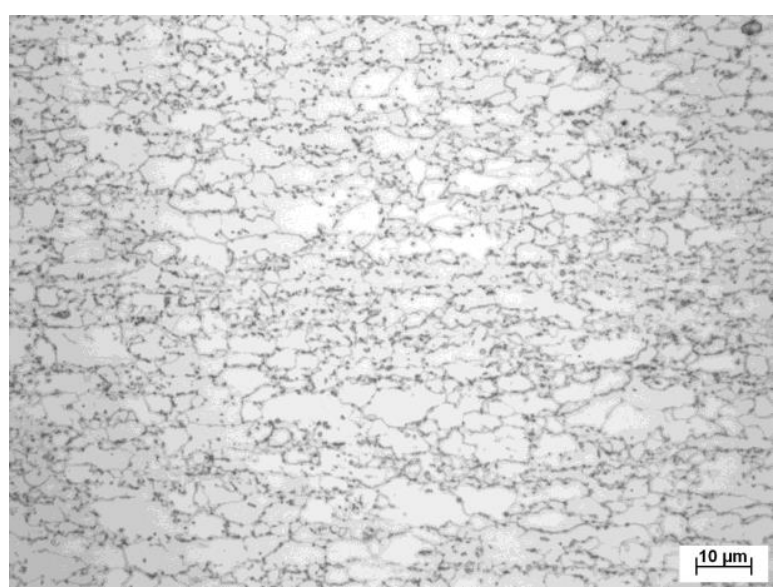

b)

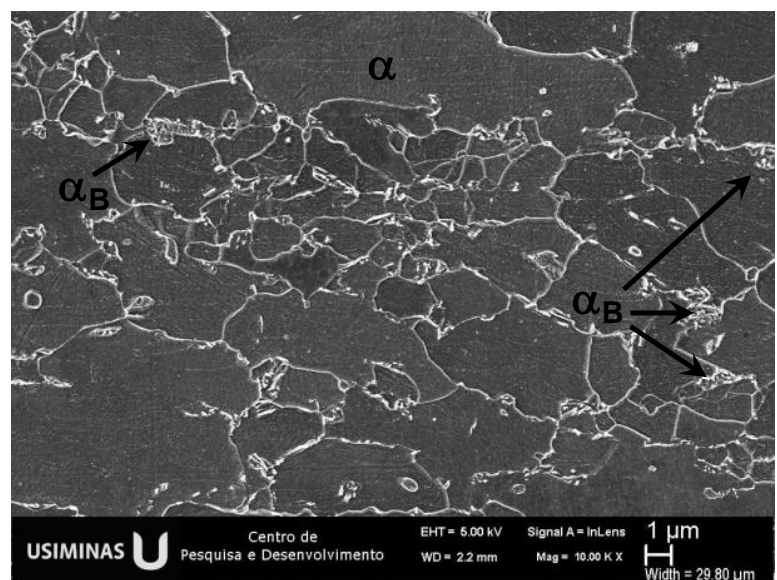

b)

Figura 5. Aspecto típico da microestrutura do material que apresentou o melhor conjunto de propriedades em escala piloto, conforme observado por microscopia óptica (a) e via MEV (b). Reativo nital $2 \%$. $\alpha$ : ferrita; $\alpha_{B}$ : bainita.

\subsection{Resultados das Experiências em Escala Industrial}

A primeira condição de processamento testada em escala industrial, denominada ciclo 01, apresentou resultados insatisfatórios de LE e de LR como mostrado na Figura 6. O ciclo 02 apresentou resultados dentro do especificado, mais próximo, porém, do limite inferior, mostrando que essa condição, pode gerar produtos não conforme devido às variabilidades dos processos de fabricação. Os resultados obtidos no ciclo 03 conseguiram alcançar valores adequados de LE, LR, Al e $\lambda$ EF. 


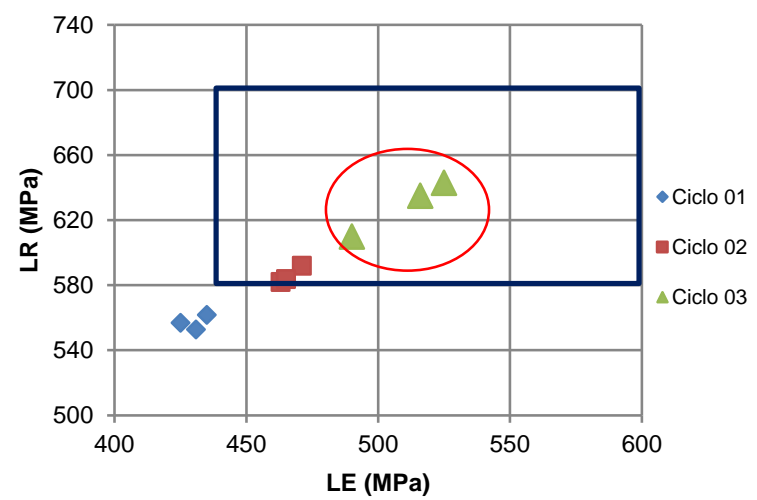

c)

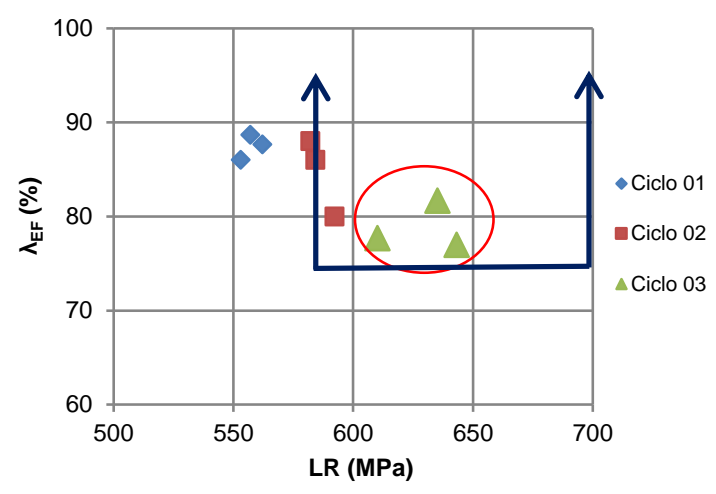

b)

Figura 6. Valores médios de LR em função de LE (a) e de $\lambda_{E F}$ (expansão cônica de furo) em função de LR (b), obtidos nos testes industriais. Em destaque o produto com melhor equilíbrio no tocante às propriedades avaliadas.

De acordo com os resultados mostrados nas Figuras 6 e 7, tanto o alongamento em tração (Alongamento50) quanto a expansão de furo ( $\lambda \mathrm{EF})$ variam inversamente com LR. Esses resultados estão de acordo com as investigações de Takahashi M [4] de que aumento de resistência mecânica deteriora essas propriedades. Outro aspecto relevante é que o aumento de LR pode levar uma maior diferença de dureza entre os constituintes microestruturais e consequentemente reduzir a expansão cônica de furo.

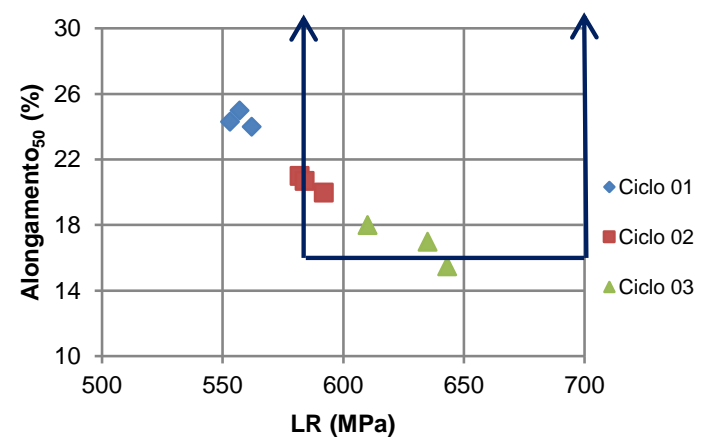

a)

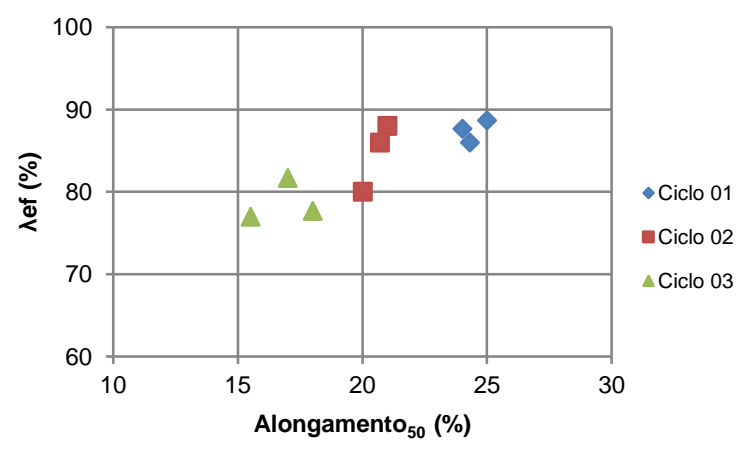

b)

Figura 7. Valores de alongamento em CPs com $50 \mathrm{~mm}$ de base de medida (Alongamento 50 ) em função de LR (a) e $\lambda$ EF em função de alongamento (b), obtidos nos testes industriais.

\subsection{Validação do Protótipo}

Cumprida a etapa de desenvolvimento em escala industrial do aço FB580-EG, algumas amostras deste produto foram testadas na manufatura de uma peça. Tratase de um componente automotivo com geometria complexa, conforme se observa na Figura 8.

Os testes foram realizados em conjunto com a Engenharia de Materiais da Fiat Chrysler Automobiles (FCA). Para efeito de comparação também se utilizou, na fabricação da peça, um aço de nível de resistência mecânica similar ao material FB580-EG, porém com baixa capacidade de expansão de furo. 

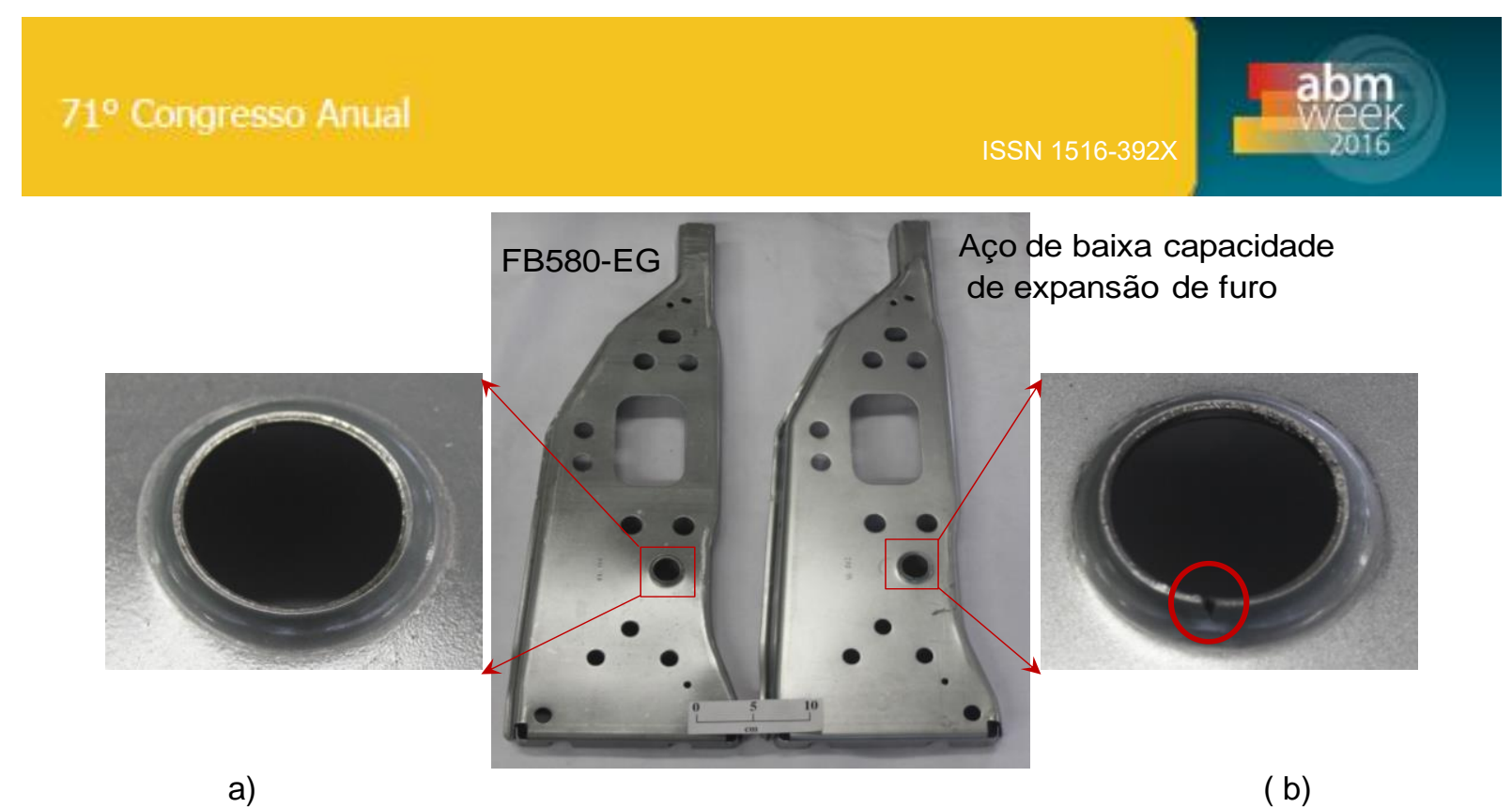

Figura 8. Aspecto de componente automotivo estampado com o aço FB580-EG e com um produto de mesmo nível de resistência, porém de baixa capacidade de expansão de furo.

Observa-se que o aço FB580-EG foi capaz de manter a integridade da peça em sua região mais crítica, Figura 8(a), ao contrário do outro produto, de mesmo nível de resistência, porém de baixa capacidade de expansão de furo, que falhou nesta mesma região, Figura 8(b).

\section{CONCLUSÃo}

Os resultados obtidos mostram que o aço FB580-EG desenvolvido atendeu ao objetivo inicial traçado, no tocante ao conjunto equilibrado de propriedades mecânicas para atender as especificações do grau FBC440Y580T da norma MS.50002 [6]. O sucesso desse desenvolvimento foi resultado da escolha de uma composição química adequada e do controle acurado das condições de processamento. Pelo fato do material atender aos requisitos do cliente, e em função dos bons resultados obtidos na estampagem de uma peça de geometria complexa, o aço FB580-EG foi homologado pela Engenharia de Materiais da FCA para ser usado em peças cuja manufatura demande elevada capacidade de flangeamento de borda e boa capacidade de alongamento, aliada à alta resistência mecânica especificada pelo projeto.

\section{REFERÊNCIAS}

1 Advanced High-Strength Steels Application Guidelines Version 5.0 - Technical Editors: Stuart Keeler, Menachem Kimchi. May, 2014.

2 Kim S, Ko K, Do H, Kang N. Development of Ultra High Strength Hot Rolled Steel with Excellent Stretch-Flange Formability. Proceedings of the Second International Symposium on Fundamentals and Applications of $\mathrm{Mo}$ and $\mathrm{Nb}$ Alloying in High Performance Steels. Held in Jeju Island, South Korea. 24-26 April 2013.

3 Matsuoka S, Hasegawa K, Tanaka Y. Newly-Developed Ultra-High Tensile Strength Steels with Excellent Formability and Weldability. JFE Technical Report. 2007; № 10: 13-18.

4 Takahashi M, Kawano O, Hayashida T, Okamoto R, Taniguchi H. High Strength Hotrolled Steel Sheets for Automobiles. Nippon Steel Technical Report. 2003; № 88: 8-12.

5 Kumar N, Singh AK, Kumar A, Patel S. High Strength Hot Rolled Steel Sheet for Automobile - A Review. IOSR Journal of Mechanical and Civil Engineering (IOSRJMCE), 2014, Volume 11, Issue 3: 53-66.

6 FCA - Sheet Steel for Automotive Application, MS.50002, August, 2015. 